Article

\title{
Design and Analysis of CCII-Based Oscillator with Amplitude Stabilization Employing Optocouplers for Linear Voltage Control of the Output Frequency
}

\author{
Roman Sotner ${ }^{1,2, *(\mathbb{D})}$, Jan Jerabek ${ }^{2}$, Lukas Langhammer ${ }^{1,2}$ and Jan Dvorak ${ }^{2}$ \\ 1 Department of Radio Electronics, Faculty of Electrical Engineering and Communication, Brno University of \\ Technology, Technicka 3082/12, Brno 616 00, Czech Republic; langhammer@phd.feec.vutbr.cz \\ 2 Department of Telecommunications, Faculty of Electrical Engineering and Communication, Brno University \\ of Technology, Technicka 3082/12, Brno 616 00, Czech Republic; jerabekj@feec.vutbr.cz (J.J.); \\ dvorakjan@phd.feec.vutbr.cz (J.D.) \\ * Correspondence: sotner@feec.vutbr.cz; Tel.: +420-541-146-560
}

Received: 29 June 2018; Accepted: 16 August 2018; Published: 22 August 2018

\begin{abstract}
This paper shows the topology design of a simple second-order oscillator based on two three-port current conveyors, two resistors, and two grounded capacitors, as well as its modification to a voltage-controlled oscillator (VCO). In comparison with many previous works, the following useful conceptual novelties and improvements were made in this study. Both resistors presented in the topology can be employed to tune of the oscillation frequency by the simultaneous driving of two optocouplers with resistive output stage. The current gain of the current conveyor ensures the control of the oscillation condition. The proposed solution offers advantages (in comparison with many standard so-called single-resistance-controllable types) of improved dependence of the frequency of oscillation (FO) on a driving force (extended tuning of the FO), constant ratio of amplitudes of generated waveforms when the FO is tuned, low complexity (taking into account auxiliary circuitry for optocouplers), and comfortable tuning of the FO by a single control voltage. The oscillator produces waveforms with tunable frequency having a constant 45-degree phase shift between them. The relative sensitivities of the proposed solution achieve typical values for these second-order systems (-0.5). Experimental verification confirmed the expected behavior in the operational band between 1 and $10 \mathrm{MHz}$ tuned by a DC voltage from 1.7 to $5 \mathrm{~V}$. This indicates a significant reduction of the driving force ratio ( $3: 1$ in our case) in comparison with standard tuning approaches required for a ratio of 10:1 for FO adjustment. Output amplitudes reached 100 and $150 \mathrm{mV}$ in the observed tunability range with distortion ranging between 0.7 and $3.3 \%$.
\end{abstract}

Keywords: current conveyors; frequency control; optocoupler; oscillator; single-resistance-controlled oscillator; SRCO; tuning; VCO

\section{Introduction}

Many recent papers have introduced interesting topologies of oscillators based on various active elements performing so-called single-resistance control of the frequency of oscillation (FO) and single-resistance control of the condition of oscillation (CO) [1]. However, single-resistance-controllable oscillators (SRCOs) [1] have many drawbacks resulting from their natural operation. The overall performance of the oscillator is influenced by adjusting the single integrator. It results in the dependence of the amplitude of one generated signal on the FO and the nonlinear dependence of the FO on the driving resistance value [1]. In some cases, phase shift between generated waves is also influenced because of the fundamental principle of operation. In recent approaches, as little as two 
resistors can be suitable for FO control (see Table 1); however, there is an issue with the independency of the $\mathrm{CO}$ when the inequality of values occurs. This issue is not solved in many works utilizing various active elements [2]. A comparison of known solutions (references [3-19]) with similar complexity (two active devices from the family of the simplest current conveyors [2] and their modifications) is given in Table 1.

We may formulate the following conclusions based on the analysis of items in Table 1:

(a) already known solutions lack constant (not varying) amplitudes when the FO is tuned (especially SRCO solutions [3-12]) or this issue was not analyzed,

(b) many solutions [3-12,15] where the first resistor serves as the FO control and the second as the $\mathrm{CO}$ control are not minimal (an additional resistor with a fixed value is included in the $\mathrm{CO}$ and FO relations simultaneously),

(c) the majority of already known solutions provide only inversely proportional square root dependence of the $\mathrm{FO}$ on the driving force (value of the single resistor, $\mathrm{FO} \sim R^{-1 / 2}$ ), which limits the tunability to be quite narrow,

(d) solutions combining control by value of passive element (or its replacement) and active parameter (for the CO control, for example) are not studied (only Reference [14] discusses the adjustment of the $\mathrm{CO}$ by an active parameter; however, the $\mathrm{FO}$ is also tuned by an active parameter $\left.\left(R_{\mathrm{X}}\right)\right)$,

(e) solutions implementing two parameters for FO tuning (completely uncoupled from the $\mathrm{CO}$ ) in order to extend tunability are not proposed (with the exception of Reference [14], where this operation was not verified),

(f) the simple implementation of necessary systems for amplitude gain control circuit (AGC) for amplitude stabilization utilizing electronically (voltage) controlled $\mathrm{CO}$ by a specific active parameter is not considered in the majority of solutions summarized in Table 1 . Therefore, many topologies have very uncomfortable $\mathrm{CO}$ (with a typical form of $C_{1}=C_{2}$ or $R_{1}=R_{2}$, and their presence is also found in the FO as product of $R_{1} R_{2}$ and $C_{1} C_{2}$, see for example solutions in $[17,18]$ ). An additional active or passive parameter suitable for the adjustment of $\mathrm{CO}$ (not included in the FO relation) should be included, but it cannot be revealed (in these simple solutions having $2 R$, $2 C$ ) without the analysis of general (not equal to unity) terminal transfer relations of the active elements (current conveyors).

In particular, the last problem (f) of the simplest published solutions (two active devices, $2 R$, $2 C)$ merits attention because there is significant room for improvement in these previously published solutions, especially concerning specific types of SRCO oscillators.

Some innovative approaches to the FO tunability can be found in topologies where resistor values cannot be used for the FO and the $\mathrm{CO}$ adjustment due to the unsuitable form of the characteristic equation. This method supposes the replacement of the negative capacitor (s) with an electronically controllable equivalent for the purposes of FO tunability [16]. However, the complete solution requires additional active devices (one or two) and additional passive elements (two or three). Therefore, such a solution is not minimal and the remaining drawbacks mentioned above still stand (dependence of generated amplitudes on the FO tuning and limited inversely proportional square root dependence of the FO on equivalent capacitance value—not analyzed in Reference [16]). 
Table 1. Comparison of solutions of the simplest resistance-controllable oscillators and single-resistance-controllable oscillator (SRCO) types based on two active elements with three-port current conveyors and grounded capacitors.

\begin{tabular}{|c|c|c|c|c|c|c|c|c|c|c|c|c|c|c|c|}
\hline 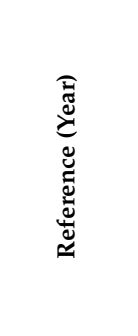 & 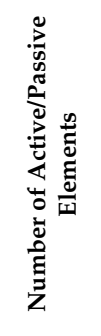 & 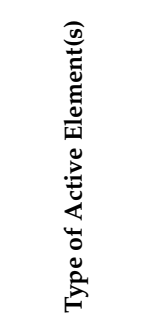 & 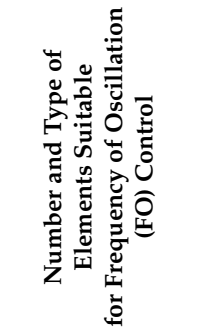 & 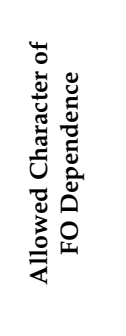 & 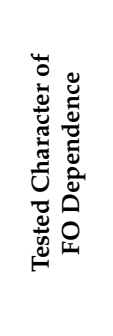 & 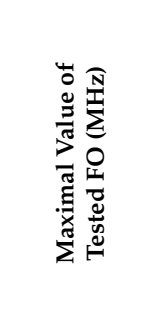 & 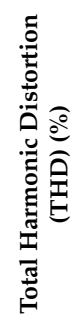 & 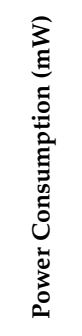 & 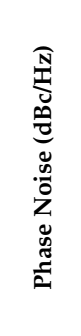 & 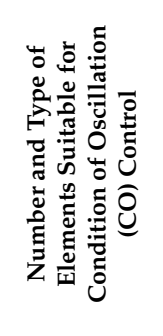 & 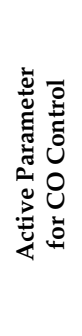 & 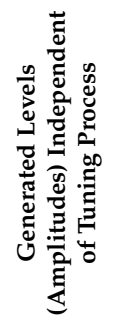 & 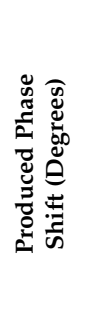 & 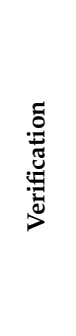 & 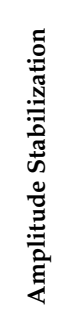 \\
\hline [3] (1995) & $2 / 5$ & $\begin{array}{l}\text { CCI+, } \\
\text { CCII- }\end{array}$ & $1 R$ grounded & $\sim R^{-1 / 2}$ & $\sim R^{-1 / 2}$ & 0.042 & $\mathrm{~N} / \mathrm{A}$ & N/A & N/A & $\begin{array}{c}1 R \\
\text { grounded }\end{array}$ & - & $\mathrm{N} / \mathrm{A}$ & $\mathrm{N} / \mathrm{A}$ & M & $\mathrm{N} / \mathrm{A}$ \\
\hline [4] (1996) & $2 / 5$ & $\begin{array}{l}\text { CCI-, } \\
\text { CCI- }\end{array}$ & $1 R$ grounded & $\sim R^{-1 / 2}$ & $\mathrm{~N} / \mathrm{A}$ & $\mathrm{N} / \mathrm{A}$ & N/A & N/A & N/A & $\begin{array}{c}1 R \\
\text { grounded }\end{array}$ & - & $\mathrm{N} / \mathrm{A}$ & $\mathrm{N} / \mathrm{A}$ & S & Yes $^{\text {a }}$ \\
\hline [5] (1996) & $2 / 5$ & CFOA & $1 R$ grounded & $\sim R^{-1 / 2}$ & $\sim R^{-1 / 2}$ & $0.460(9.85)^{\mathrm{I}}$ & N/A & N/A & N/A & $\begin{array}{c}1 R \\
\text { grounded }\end{array}$ & - & N/A & N/A & M & N/A \\
\hline [6] (1997) & $2 / 5$ & CFOA & $1 R$ grounded & $\sim R^{-1 / 2}$ & $\sim R^{-1 / 2}$ & 6.00 & $<1$ & N/A & N/A & $\begin{array}{c}1 R \\
\text { grounded }\end{array}$ & - & N/A & N/A & M & N/A \\
\hline [7] (1998) & $2 / 5$ & CFOA & $1 R$ grounded & $\sim R^{-1 / 2}$ & $\sim R^{-1 / 2}$ & N/A & $\mathrm{N} / \mathrm{A}$ & N/A & N/A & $\begin{array}{c}1 R \\
\text { grounded }\end{array}$ & - & N/A & N/A & N/A & N/A \\
\hline [8] (1998) & $2 / 5$ & CFOA & $1 R$ grounded & $\sim R^{-1 / 2}$ & $\mathrm{~N} / \mathrm{A}$ & 0.260 & $\mathrm{~N} / \mathrm{A}$ & N/A & N/A & $\begin{array}{c}1 R \\
\text { grounded }\end{array}$ & - & $\mathrm{N} / \mathrm{A}$ & N/A & M & N/A \\
\hline [9] (1999) & $2 / 6(5)$ & $\begin{array}{l}\text { CCII+, } \\
\text { CCII- }\end{array}$ & $2 R$ grounded & $\sim R^{-1}$ & $\mathrm{~N} / \mathrm{A}$ & 0.153 & $\mathrm{~N} / \mathrm{A}$ & N/A & N/A & $\begin{array}{c}2 R \\
\text { grounded }\end{array}$ & - & N/A & 90 & S & N/A \\
\hline [10] (2005) & $2 / 6$ & $\begin{array}{c}\text { CCII+ } \\
\text { (CFOA) }\end{array}$ & $1 R$ grounded & b & b & 0.189 & 1.5 & N/A & N/A & $1 R$ floating & - & N/A & N/A & S & N/A \\
\hline [11] (2006) & $2 / 5$ & CFOA & $\begin{array}{l}1 R \text { floating or } \\
\text { grounded }{ }^{\mathrm{C}}\end{array}$ & $\sim R^{-1 / 2}$ & $\sim R^{-1 / 2}$ & 0.037 & $<3.1$ & N/A & N/A & c & - & N/A & N/A & M & N/A \\
\hline [12] (2009) & $2 / 5$ & CFOA & $1 R$ grounded & $\sim R^{-1 / 2}$ & $\sim R^{-1 / 2}$ & $290(609)^{\mathrm{II}}$ & 1.6 & N/A & N/A & $\begin{array}{c}1 R \\
\text { grounded }\end{array}$ & - & N/A & $\mathrm{N} / \mathrm{A}$ & M & $\mathrm{N} / \mathrm{A}$ \\
\hline [13] (2010) & $2 / 4$ & CFOA & d & $\sim R^{-1 / 2}$ & $\mathrm{~N} / \mathrm{A}$ & N/A & $\mathrm{N} / \mathrm{A}$ & $\mathrm{N} / \mathrm{A}$ & $\mathrm{N} / \mathrm{A}$ & d & - & $\mathrm{N} / \mathrm{A}$ & N/A & $\mathrm{M}$ & N/A \\
\hline [14] (2010) & $2 / 2$ & $\mathrm{CCCII+/-}$ & $2 R_{\mathrm{X}}$ & $\sim R^{-1}$ & $\sim R^{-1 / 2}$ & 1.80 & $<7$ & 3.5 & N/A & - & $B$ & N/A & $\mathrm{N} / \mathrm{A}$ & $\mathrm{S}$ & N/A \\
\hline [15] (2011) & $2 / 5$ & CFOA & $1 R$ grounded & $\sim R^{-1 / 2}$ & $\mathrm{~N} / \mathrm{A}$ & 1.320 & $<3$ & N/A & $\mathrm{N} / \mathrm{A}$ & $1 R$ floating & - & $\mathrm{N} / \mathrm{A}$ & $\mathrm{N} / \mathrm{A}$ & $\mathrm{M}$ & $\mathrm{N} / \mathrm{A}$ \\
\hline [16] (2011) & $2 / 4$ & $\mathrm{CFOA}$ & $1 C_{\mathrm{eq}}$ grounded & $\sim C_{\mathrm{eq}}{ }^{-1 / 2}$ & N/A & 0.146 & $<2$ & N/A & $\mathrm{N} / \mathrm{A}$ & $2 R$ floating * & - & N/A & 90 & $\mathrm{~S}$ & N/A \\
\hline [17] (2012) & $2 / 4$ & $\begin{array}{l}\text { DO-(I)CCII, } \\
\text { CCI }\end{array}$ & $\begin{array}{l}2 R \text { floating and } \\
\text { grounded }\end{array}$ & $\sim R^{-1}$ & $\sim R^{-1 / 2}$ & 0.182 & $<1.7$ & N/A & N/A & $\mathrm{e} *$ & - & No & 90 & $\mathrm{~S}$ & N/A \\
\hline
\end{tabular}


Table 1. Cont.

\begin{tabular}{|c|c|c|c|c|c|c|c|c|c|c|c|c|c|c|c|}
\hline 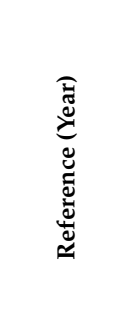 & 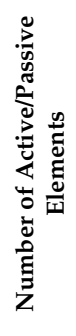 & 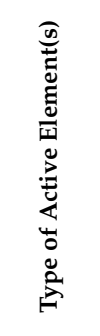 & 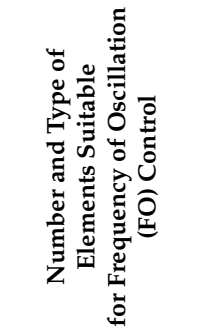 & 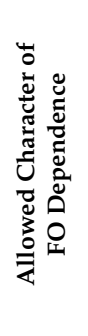 & 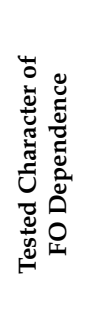 & 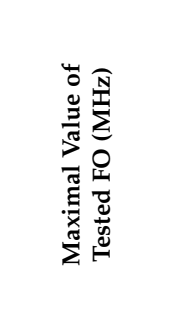 & 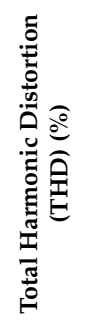 & 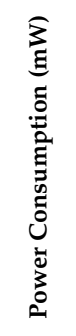 & 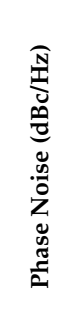 & 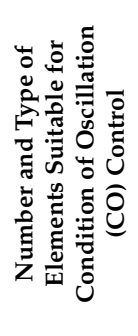 & 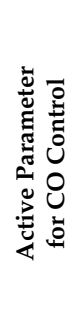 & 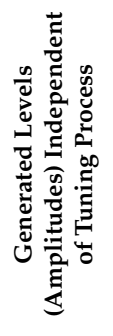 & 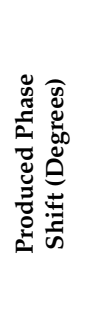 & 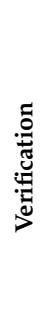 & 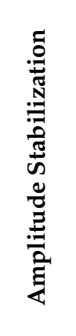 \\
\hline [18] (2014) & $2 / 4$ & CFOA & $2 R$ floating & $\sim R^{-1}$ & $\mathrm{~N} / \mathrm{A}$ & $0.065(1.33)^{\mathrm{III}}$ & $<0.8$ & 0.86 & $\mathrm{~N} / \mathrm{A}$ & * & - & Yes & 90 & $\mathrm{~B}$ & $\mathrm{~N} / \mathrm{A}$ \\
\hline [19] (2011) & $2 / 6$ & CCII+ & $\begin{array}{c}2 R \text { floating and } \\
\text { grounded }\end{array}$ & $\sim R^{-1}$ & $\mathrm{~N} / \mathrm{A}$ & 1.43 & $<0.3$ & N/A & N/A & $* *$ & - & N/A & N/A & M & Yes \\
\hline Figure 1 & $2 / 4$ & $\begin{array}{l}\text { CCII-, } \\
\text { ECCII+ }\end{array}$ & $\begin{array}{l}2 R \text { floating and } \\
\text { grounded }\end{array}$ & $\sim R^{-1}$ & $\sim R^{-1}$ & $10.3(25.0)^{\mathrm{IV}}$ & $<3.3$ & $570^{\mathrm{V}}$ & $>45$ & - & B & Yes & 45 & M & Yes \\
\hline
\end{tabular}

Notes: CCI+/-—current conveyor of the first (negative/positive output) generation; ICCII-inverting current conveyor of the second generation; DO-(I)CCII—dual output (I)CCII; $\mathrm{CCCII}+$ /- - current controlled CCII+/-; ECCII+/-—electronically controllable CCII+/-; CFOA—current feedback amplifier. Active parameters: $R_{X}$-internal resistance of terminal X (current conveyor); $B$-adjustable current gain between $X$ and $Z$ terminal of ECCII. ${ }^{a}$ Antiparallel diodes; ${ }^{b}$ complicated matching condition (resistor ratio) for tuning; ${ }^{\mathrm{c}}$ several various solutions presented in Reference [11], not all of them have easily uncoupled $\mathrm{CO}$ and $\mathrm{FO}$; ${ }^{\mathrm{d}}$ complex relations for $\mathrm{FO}$ and $\mathrm{CO}$, some of them have uncoupled $\mathrm{FO}$ and $\mathrm{CO}$ independently controllable by grounded resistors; ${ }^{e}$ sometimes uncomfortable condition for $\mathrm{CO}$ (equality/matching of two capacitors/resistors required, no further parameter available for driving of CO), independence of generated levels (amplitudes) on FO confirmed analytically; ${ }^{*}$ problematic FO tuning and CO adjusting by matching of two resistors $\left(R_{1}=R_{2}\right.$ or $C_{1}=C_{2}$ for CO driving and $R_{1} R_{2}$ for FO tuning); ${ }^{* *}$ matching of two resistors intended for FO must be ensured for uncoupled CO control by different pair of resistors; ${ }^{\mathrm{I}}$ up to $9.85 \mathrm{MHz}$ without working capacitors (used with parasitic nodal capacitances only); ${ }^{\text {II }} 609 \mathrm{kHz}$ available for $0.5 \mathrm{nF}$ values of capacitors; ${ }^{\text {III }}$ measured at $65 \mathrm{kHz}$ with commercial element, simulated with CMOS topology of active device at $1.33 \mathrm{MHz}$; ${ }^{\mathrm{IV}}$ high corner of tunability range set to $10.3 \mathrm{MHz}$ but $25 \mathrm{MHz}$ available when external $C_{1,2}=4.7 \mathrm{pF}$ applied, ${ }^{\mathrm{V}}$ this value includes power consumption of all devices on experimental printed circuit board (PCB) (also voltage buffers, automatic gain control circuit for amplitude stabilization (AGC), etc.); M-measured; S-simulated, B-both; N/A—not available, not tested. 
The controllability of the FO by two values of resistors (completely uncoupled from the CO) is possible in topologies proposed by Soliman [9]. However, three active devices (CCII+ and CCII-) or two dual output CCIIs (not commercially available) are required. The condition of oscillation can also be controlled by two resistors that are not presented in the equation for the FO. Note that the engagement of both resistors (suitability derived from characteristic equations) in References $[9,14,17,18]$ for full employment in FO tuning is not supposed and tested in these works. In addition, the majority of solutions focus on a quadrature type of phase shift; different phase shifts are not expected to be obtained in these structures, but it is possible as shown in our contribution. Work presented by Bajer et al. [19] introduced a new type of Wien oscillator. The FO cannot be simply tuned without impact on the $\mathrm{CO}$ if a special matching condition is not fulfilled (unfortunately, the FO adjustment was not tested). Amplitude stabilization (with the exception of many other circuits included in Table 1) is solved by an optocoupler regulating floating resistor.

The goals of our work include the proposal of: (1) improved dependence of the FO on the driving force (extended tuning of the FO) in comparison with standard SRCO types; (2) constant amplitude ratio of generated waveforms when the FO is tuned; (3) using only grounded capacitors in topology; (4) only two active elements, only two capacitors, and two resistors employed in the circuitry; (5) simple implementation of AGC; (6) comfortable tuning of the FO by a single control voltage-a voltage-controlled oscillator (VCO); and (7) constant phase shift (45 degrees) during the tuning of the FO. Point (6) particularly requires the careful selection and testing of known methods for the replacement of the resistor with an electronically controllable equivalent. We selected a rather nonstandard method (optocoupler with resistive output stage) that has not been frequently used for these purposes in the past but brings certain advantages (no significant additional power consumption, not comparable with standard commercially available active devices, good linearity, good frequency features).

The novelty of the presented circuit is revealed by the following features: (a) values of both external resistors presented in a topology of the oscillator topology are suitable for tuning purposes; (b) permitted voltage-controlled linear tuning of frequency that is not possible in the case of many previously published and similar topologies known as single-resistance-controlled methods; (c) no further "dummy" resistors or resistors suitable for the control of the oscillation condition occur in the presented topology; (d) comfortable control of the condition of oscillation by a single active parameter (current gain) independent from frequency; (e) optocouplers with the resistive output stage offer less distorted output waveforms and more precise tuning of the frequency (even when one of the resistors occurs in the floating form) than the field effect transistor (FET), which is not easily applicable in the floating form; and (f) the method of electronic control (voltage driving of optocouplers) improves the ratio of the frequency readjustment (tuning) vs. the driving force ratio.

This paper is organized as follows: Section 1 introduces the topic of resistance-controllable oscillators and provides an overview of significant solutions and their features with respect to our intentions in the above defined goals. Section 2 compares the parameters and available features of the two most similar solutions and our proposal in detail. Section 3 discusses reasons for the selection of the implemented method of resistance control. Section 4 analyses the discussed solution of the oscillator (features of controllability). Section 5 provides a precise explanation of the design and features of the component parameters as well as the experimental results of the circuit behavior when the FO is tuned and their comparison to the expectations and ideal theory. Further methods of the indirect electronic tunability (replacements of resistors) are briefly evaluated and compared in Section 6 . Section 7 concludes this work.

\section{Detailed Qualitative Comparison of the Most Similar Solutions and the New Proposal}

The following section explains the main differences of the newly proposed circuit and the most similar solutions (topologically) already presented. Kumngern et al. [14] proposed a similar topology of the oscillator where the target adjustability of the FO was solved by driving the intrinsic resistance of the input terminal $X\left(R_{X}\right)$ by the bias current. This means that external resistors are not present in 
the solution [14]. Unfortunately, current conveyors with controllable internal resistance $R_{\mathrm{X}}$ are not available on the market. The control of the bias current (in order to adjust $R_{X}$ ) also has a significant impact on the frequency bandwidth (transfer $Y \rightarrow X$ ), input dynamics, and linearity as well as the output resistance of the current conveyor (unintentional but unavoidable) [20]. Then, the range of $R_{X}$ value can be very limited. This results in a reduced range of FO tunability. Therefore, our contribution, by solving the tunability of the FO with external replacements of both resistors, brings improvement to the common practice (especially owing to the very low ratio of the driving force vs. the ratio of FO readjustability, see Table 2). The CO in Reference [14] also proposes adjusting by the bias current, setting a gain between the $X$ and $Z$ terminals of the current conveyor. Unfortunately, the implementation of the topology as a two-phase oscillator as well as the analysis of the output relation has not been performed and only a single-resistance $R_{X}$ was employed for the FO tuning. This results in an inversely proportional square root dependence of the FO on $R_{X}$, i.e., limited tunability. Therefore, the full potential of the topology was not revealed and tested in Reference [14]. A very low output amplitude (only slightly more than $20 \mathrm{mV}$ ) was also obtained in the results of Reference [14]. Our solution offers a larger output level (amplitudes more than $100 \mathrm{mV}$ ). All these aspects (and more details) are clearly visible in Table 2. Lahiri [17] proposed a very similar (topologically) circuit (Figure 1a in Reference [17]), producing output signals in current form. However, the topology also had high-impedance nodes where the output voltages were presented. Several features, compared in Table 2, are similar to those of Reference [14] and our proposal (number of active and passive elements, character of allowed and tested FO dependence). Nevertheless, the range of tested tunability is very narrow (narrow change of resistance value = low ratio of FO readjustability), CO cannot be electronically controlled, and the generated levels are not independent from the tuning process. Other similar solutions (listed in Table 1) do not provide detailed information about the features required for the comparison in Table 2. Therefore, other solutions are not included in this detailed comparison (Table 2).

Table 2. Comparison of our solution and topologically similar circuits in References [14,17] based on two current conveyors and two grounded capacitors.

\begin{tabular}{|c|c|c|c|}
\hline Reference & [14] & [17] (Figure 1a) & Proposed (Figure 1) \\
\hline No. of passive elements & 2 & 4 & 4 \\
\hline No. of elements (parameters) suitable for FO control & 2 & 2 & 2 \\
\hline No. of elements (parameters) used for FO control & 1 & 1 & 2 \\
\hline Solution of FO control & $\begin{array}{l}\text { resistance }\left(R_{X}\right) \\
\text { of } X \text { terminal }\end{array}$ & $\begin{array}{l}\text { external resistance value (in } \\
X \text { terminal of conveyor) }{ }^{*}\end{array}$ & $\begin{array}{l}\text { resistances of } \\
\text { optocouplers }\end{array}$ \\
\hline Allowed character of FO dependence & $\sim R^{-1}$ & $\sim R^{-1}$ & $\sim R^{-1}$ \\
\hline Tested character of FO dependence & $\sim R^{-1 / 2}$ & $\sim R^{-1 / 2}$ & $\sim R^{-1}$ \\
\hline Range of driving force & $1 \mu \mathrm{A} \rightarrow 500 \mu \mathrm{A}$ & $8 \mathrm{k} \Omega \rightarrow 15 \mathrm{k} \Omega$ * & $1.73 \rightarrow 4.95 \mathrm{~V}$ \\
\hline Ratio of driving force & $\begin{array}{l}500: 1 \text { (bias } \\
\text { current) }\end{array}$ & $1.9: 1 *$ & 3:1 (control voltage) \\
\hline Obtained FO range $(\mathrm{MHz})$ & $0.2 \rightarrow 1.8$ & $0.120 \rightarrow 0.165$ & $1.05 \rightarrow 10.30$ \\
\hline Ratio of FO & $9: 1$ & $1.4: 1$ & $10: 1$ \\
\hline Active parameter for $\mathrm{CO}$ control & Yes & No & Yes \\
\hline Type of active parameter suitable for CO control & current gain & $\mathrm{N} / \mathrm{A}$ & current gain \\
\hline Outputs (nodes) used & 1 & 2 & 2 \\
\hline Produced phase shift $\left({ }^{\circ}\right)$ & $\mathrm{N} / \mathrm{A}$ & 90 & 45 \\
\hline Amplitude stabilization & $\mathrm{N} / \mathrm{A}$ & $\mathrm{N} / \mathrm{A}$ & Yes \\
\hline $\begin{array}{l}\text { Generated levels (amplitudes) independent on } \\
\text { tuning process }\end{array}$ & $\mathrm{N} / \mathrm{A}$ & No & Yes \\
\hline Output amplitude & $25 \mathrm{mV}$ & $80 \rightarrow 125 \mu \mathrm{A}, 95 \rightarrow 110 \mu \mathrm{A}$ & $100 \mathrm{mV}, 150 \mathrm{mV}$ \\
\hline THD (\%) & $1 \rightarrow 7$ & $0.7 \rightarrow 1.4$ & $0.7 \rightarrow 3.3$ \\
\hline Verification & simulated & simulated & measured \\
\hline
\end{tabular}

* There is no driving force (voltage, current), the value of the grounded resistor is changed from $8 \mathrm{k} \Omega$ to $15 \mathrm{k} \Omega$. 


\section{Implementation of Optocouplers for Control of VCO}

Many possible solutions of electronically controllable replacements of resistors are available for designers. Their brief comparison is given in Section 6. We selected the implementation of optocouplers because their applications for purposes of tuning are beneficial in comparison with the standard utilization of unipolar transistors in a triode/ohmic regime (see for example [11,12]). Moreover, the implementation of unipolar transistors in floating connections between nodes is not an easy task (additional active and passive elements are required) [11,12]. The application of optocouplers in oscillators was introduced by Bajer et al. [19] and Biolkova et al. [21]. These devices have been employed to stabilize the amplitude of sine waveforms. Our intentions in this paper are quite different. Optocouplers are expected to be used for tuning purposes (to replace resistors suitable for the FO tuning). The circuit solution in this paper is suited for application of optocouplers more than for unipolar transistors because of the presence of grounded as well as floating resistors intended to tune the FO in the topology.

\section{Topology Suitable for Selected Method of FO Control}

Figure 1 shows the topology of the oscillator utilizing only two active devices, two grounded capacitors, and two resistors (the most similar solution [14] omits external resistors with full consideration of the issues discussed in a previous text). The negative current conveyor of the second generation (CCII-) $[2,22]$ as well as a positive electronically controllable CCII (ECCII+) $[2,22-25]$ have identical definitions of two inter-terminal relations- $I_{Y}=0, V_{X}=V_{Y}$-whereas the most important difference rests in the transfer of the current from the $X$ to $Z$ terminals $\left(I_{Z}=-I_{X}\right.$ for CCII- and $I_{Z}=B \cdot I_{X}$ for ECCII+). The parameter $B$ represents a generally adjustable current gain. The characteristic equation of this simple oscillator is:

$$
s^{2}+\frac{C_{2}-C_{1} B}{R_{1} C_{1} C_{2}} s+\frac{1}{R_{1} R_{2} C_{1} C_{2}}=0
$$

This characteristic equation offers a very beneficial condition for oscillation $B \geq C_{2} / C_{1}$. The most important advantage of the solution results from the mutually independent $\mathrm{CO}$ and the FO, completely defined by the values of both capacitors and resistors having the typical form of $\omega_{0}=\left(R_{1} R_{2} C_{1} C_{2}\right)^{-1 / 2}$.

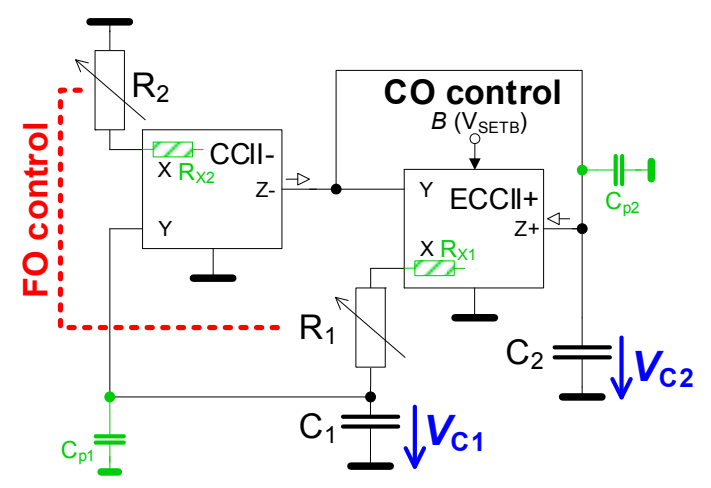

Figure 1. Simple oscillator employing two current conveyors, two capacitors, and two resistors.

The relation between the generated output voltage levels (amplitudes) can be expressed as:

$$
\frac{V_{C 1}}{V_{C 2}}=\left.\frac{1}{1+s C_{1} R_{1}}\right|_{s=j \omega_{0}} \Rightarrow \frac{1-j \sqrt{\frac{R_{1} C_{1}}{R_{2} C_{2}}}}{\left(1+\sqrt{\frac{R_{1} C_{1}}{R_{2} C_{2}}}\right)},
$$

which can be modified into: 


$$
V_{C 1}=\frac{\sqrt{1+\frac{R_{1} C_{1}}{R_{2} C_{2}}}}{\left(1+\sqrt{\frac{R_{1} C_{1}}{R_{2} C_{2}}}\right)} \exp \left[j \cdot \tan ^{-1}\left(-\sqrt{\frac{R_{1} C_{1}}{R_{2} C_{2}}}\right)\right] V_{C 2} .
$$

Supposing the equality of both resistors and capacitors $\left(R_{1}=R_{2}=R, C_{1}=C_{2}=C\right)$, the previous relation can be simplified to:

$$
V_{C 1}=\frac{\sqrt{2}}{2} \exp \left(-j \frac{\pi}{4}\right) V_{C 2}
$$

The proposed oscillator theoretically offers a constant level of output amplitudes with a constant ratio of 0.707 between the generated waveforms and a phase shift of 45 degrees, while the FO is tuned by $R_{1}$ and $R_{2}$ simultaneously. Note that the controllability of the FO by a single value $\left(R_{1}\right.$ or $\left.R_{2}\right)$ causes amplitude and phase shift changes (when the FO is tuned). Valuable engagement of both resistors for the FO control is not a typical feature in such simple circuitries (Figure 1). This represents a very important finding in comparison with standard SRCOs and other solutions [1,3-12] tunable by a single parameter value only. Moreover, the dependence of the generated output level on the tuning process (variation of the parameter intended for the FO tuning) presents an unwanted secondary effect of the single-parameter controllability of the FO [26]. It brings additional issues with amplitude limitation and distortion. In our case, this was not an issue.

The most important small-signal parasitic effects of real circuitry (indicated by green color in Figure 1) are easily taken into account in a modified form of Equation (1) where the parasitic (stray) nodal capacitances $C_{p 1}, C_{p 2}$ (in parallel to $C_{1}, C_{2}$ ) and resistances $R_{X 1}, R_{X 2}$ of the current input terminals (in $X$ of both current conveyors) are considered:

$$
\begin{gathered}
s^{2}+\frac{\left(C_{2}+C_{p 2}\right)-\left(C_{1}+C_{p 1}\right) B}{\left(R_{1}+R_{X 1}\right)\left(C_{1}+C_{p 1}\right)\left(C_{2}+C_{p 2}\right)} s+\frac{1}{\left(R_{1}+R_{X 1}\right)\left(R_{2}+R_{X 2}\right)\left(C_{1}+C_{p 1}\right)\left(C_{2}+C_{p 2}\right)}=0 . \\
B^{*} \geq \frac{C_{2}+C_{p 2}}{C_{1}+C_{p 1}}, \\
\omega_{0}^{*} \cong \frac{1}{\sqrt{\left(R_{1}+R_{X 1}\right)\left(R_{2}+R_{X 2}\right)\left(C_{1}+C_{p 1}\right)\left(C_{2}+C_{p 2}\right)}} .
\end{gathered}
$$

This equation was gained by the routine analysis of an autonomous circuit including the most important parasitic elements in Figure 1 (indicated by green color). The new $\mathrm{CO}$ and FO expressions (difference from ideal CO and FO indicated in superscript ${ }^{*}$ ) can be derived from Equation (5a) as follows. The equation for $\omega_{0}{ }^{*}(5 \mathrm{c})$ provides the expected values of FO used in Equation (8) and shown in Table 3 when the oscillator is tuned. The relative sensitivity of the FO to the main parameters $\left(R_{1}, R_{2}\right.$, $\left.C_{1}, C_{2}\right)$, in an ideal case derived from (1), reaches a typical value of -0.5 . The sensitivities of the FO, including the effect of important parasitic parameters presented in (5c), are: $S_{R 1} \omega 0 *=-R_{1} /\left[2 \cdot\left(R_{1}\right.\right.$ $\left.\left.+R_{x 1}\right)\right], S_{R 2} \omega 0 *=-R_{2} /\left[2 \cdot\left(R_{2}+R_{x 2}\right)\right], S_{C 1} \omega 0 *=-C_{1} /\left[2 \cdot\left(C_{1}+C_{p 1}\right)\right], S_{C 2} \omega 0 *=-C_{2} /\left[2 \cdot\left(C_{2}+C_{p 2}\right)\right]$, $S_{R x 1} \omega 0 *=-R_{x 1} /\left[2 \cdot\left(R_{1}+R_{x 1}\right)\right], S_{R x 2} \omega 0 *=-R_{x 2} /\left[2 \cdot\left(R_{2}+R_{x 2}\right)\right], S_{C p 1} \omega 0 *=-C_{p 1} /\left[2 \cdot\left(C_{1}+C_{p 2}\right)\right]$. In fact, these sensitivities have absolute values lower than those of the ideal case $(<0.4$ numerically for particular values from our design).

Note that many commercially available types of current conveyors have very high $(\mathrm{M} \Omega)$ resistances (real parts of voltage inputs and current outputs) at the $Y$ and $Z$ terminals [27] and their inclusion to (5a) does not create a significant effect in comparison with the $C_{p 1,2}$ and $R_{X 1,2}$ in this case. However, there are solutions where these effects cannot be omitted and full consideration of all parasitic features must be provided for the accurate estimation of behavior at high frequencies and when the value of $C_{1,2}$ is set in hundreds of $\mathrm{pF}$ or lower. The specific values of $C_{p 1,2}$ for our case are discussed in the next section. 


\section{Design of Oscillator and Results of Experiments}

The initial design of this circuit supposes $C_{1}=C_{2}=C=47 \mathrm{pF}$. Note that this selection (tens of $\mathrm{pF})$ is generally required in combination with resistance values $\left(R_{1}=R_{2}=R\right)$ in hundreds of $\Omega$ for the operation of this and similar oscillators above $1 \mathrm{MHz}$. However, the values of working capacities are not far from the values of stray capacitances of circuitry including the terminal capacities of active devices (units of $\mathrm{pF}$ ). The internal value of $X$ terminals of CCIIs $\left(R_{X 1,2}\right)$ must also be taken into account from Equation (5a) and (5c). The current conveyors used in our topology (Figure 1) are established by current-mode multipliers EL2082 [27] and a high-speed single-input single-output transconductance amplifier known also as a diamond transistor OPA615 [28]. The electronically controllable gain $B$ (proportionally driven by $V_{\text {SETB }}$ voltage: $B \cong V_{\text {SETB }}$ for $V_{\text {SETB }} \leq 2 \mathrm{~V}$ [27]; because $B \cong k \cdot V_{\mathrm{SETB}}$, where $k=1\left[\mathrm{~V}^{-1}\right]$ is valid for $V_{\mathrm{SETB}} \leq 2 \mathrm{~V}$ ) of EL2082 was set to $B=1$ for CCII- operation. The cascade of EL2082 with OPA615 (output inversion of CCII-) creates ECCII+ type where $B$ can be controlled to drive the CO by an external AGC for the amplitude stabilization of the generated waveforms (Figure 2). The main purpose of the AGC consists in the sustentation of unchangeable output levels when the oscillator is tuned. This feature cannot be simply obtained when the CO is set to fulfill an analytically obtained relation because energetic (gain) proportions in the circuit are influenced by tunability. The operation without AGC leads to issues with output waveforms (damage of the shape by nonlinear transfer responses of active devices or even limitation), resulting in high total harmonic distortion (THD) (increased level and amount of higher harmonic components and increased level of spurious combination products) or fading (drop down) of oscillations. Voltage buffers (not included in the simplified schemes), based on the OPA2652 [29] operational amplifier, are added to high-impedance nodes for the impedance separation and subsequent measurement of the circuit on a printed circuit board (PCB) by a low-input-impedance $(50 \Omega)$ spectrum analyzer HP4395A and oscilloscope Rigol DS1204B.

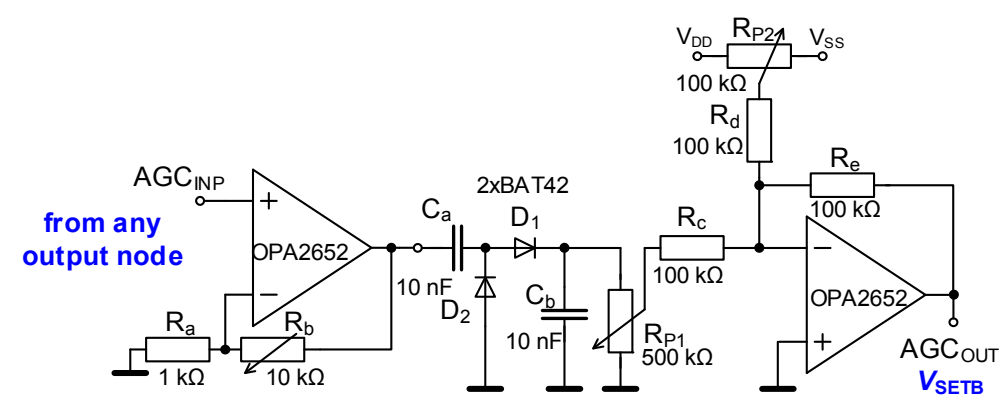

Figure 2. Simplified topology of AGC circuit for amplitude stabilization.

Expected values of stray/parasitic capacitances are $C_{p 1}=3 \mathrm{pF}$ and $C_{p 2}=10 \mathrm{pF}$ (in parallel with $C_{1}$ and $C_{2}$ ) where $C_{p 1}$ includes the $Y$ terminal capacity $2 \mathrm{pF}$ (CCII-) [27] and input capacity of voltage buffer (1 pF) [29]. The estimated effect of $C_{p 2}$ supposes a capacity of $5 \mathrm{pF}$ of the $Z$ terminal (CCII-) [27] and the $Y, Z$ terminals $(2+2 \mathrm{pF})$ of ECCII+ [28], as well as the input capacity of the voltage buffer $(1 \mathrm{pF})$. Terminal $X$ has an expected input resistance $R_{\mathrm{X} 1,2}=95 \Omega$ [27].

FO tuning can be achieved by the variation of $R_{1}$ and $R_{2}$ values simultaneously by a dual-channel tandem potentiometer. Our design intention targets tunability in the approximate range of 1-10 MHz. The discussed method (potentiometer) is not very comfortable for standard applications. Many systems produce a DC driving voltage or current (after D/A conversion). Therefore, we seek useful methods of indirect electronic control. The following paragraphs deal with the possible improvement of the circuit to VCO.

The position of the $R_{1}$ resistor in the topology (Figure 1) of the oscillator requires the implementation of controllable resistance in a floating form. The replacement of $R_{1}$ by the emulator based on active devices, for example, operational transconductance amplifiers (OTAs) [30,31], brings significant additional power 
consumption, area, and further complications. Therefore, we selected the optocoupler NSL-32SR3 [32] (photodiode-photoresistor) with very favorable features (frequency bandwidth and linearity) in a grounded or floating form in comparison with many active solutions (unipolar transistors in a linear regime). Our circuit (Figure 1) employs two optocouplers as shown in Figure 3.

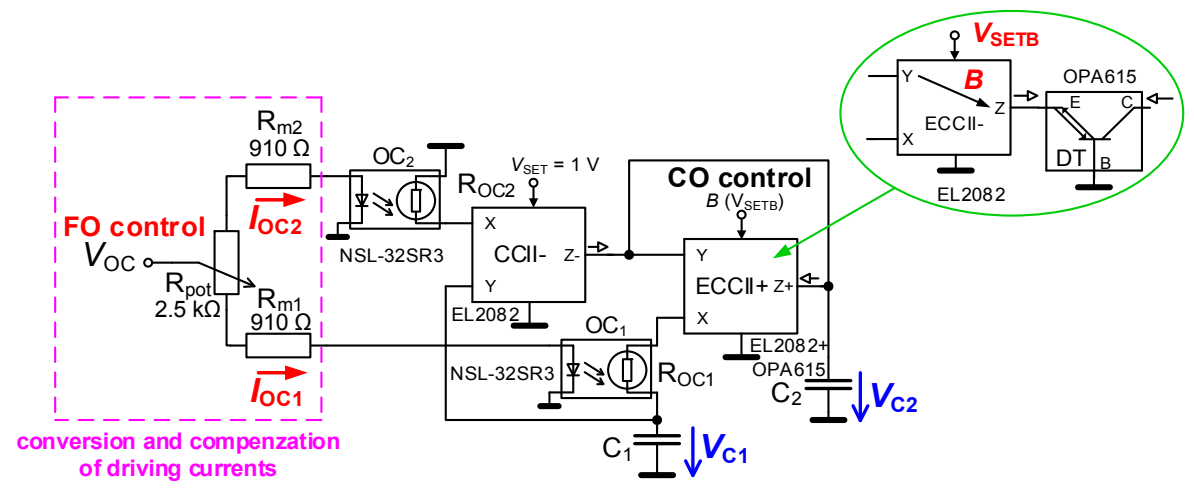

Figure 3. Indirect electronic control of the FO in the oscillator performed by two optocouplers.

The reasons for the presence of $R_{m 1,2}=910 \Omega$ and $R_{\text {pot }}=2.5 \mathrm{k} \Omega$ result from the required transformation $\left(R_{m 1,2}\right)$ of the driving voltage $V_{O C}$ to currents with a maximal allowed value (here approximately $1.5 \mathrm{~mA}$ per branch, which is approximately more than 10 times lower current consumption than opamp or CCII per single supply branch, for $V_{O C}=5 \mathrm{~V}$-fully positive supply voltage) and the compensation for the slight inequality of the resulting $R_{O C 1}$ and $R_{O C 2}$ (given by fabrication mismatch) for the same driving current. We compensated this effect by the slight inequality of driving currents $\left(I_{O C 1} \neq I_{O C 2}\right)$. The threshold voltage $V_{t h} \approx 1.6 \mathrm{~V}$ of the optocoupler's LED was obtained experimentally. The measured frequency features (by vector network analyzer E5071C) of the optocoupler output $\left(Z_{O C}\right)$ are introduced in Figure 4 for particular values. Figure 5 shows the dependence of $R_{O C}$ on the driving current and voltage (in accordance with the driving circuitry in Figure 3). The datasheet [32] does not publish these features, but they must be known for the design of applications. Features of the device limit its implementation to systems operating around $10 \mathrm{MHz}$ when the value of $R_{O C}$ is set below $500 \Omega$. Based on our experiments, the relation between $R_{O C}$ and the driving current $I_{O C}$ can be found empirically as $R_{O C}[\Omega] \cong 0.2 / I_{O C}[\mathrm{~A}]$. Then $R_{O C}$ can be approximately expressed, in dependence on the driving voltage $V_{O C}$, as:

$$
R_{O C i} \cong 0.2 \cdot\left(\frac{0.5 R_{p o t}+R_{m 1,2}}{V_{O C}-V_{t h}}\right)
$$

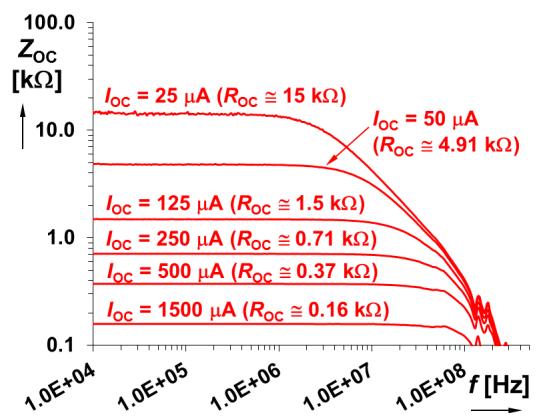

(a)

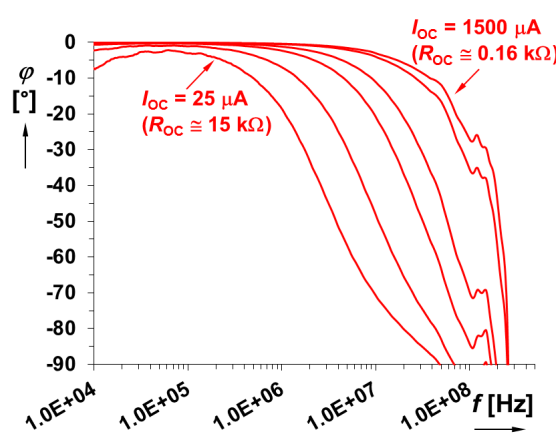

(b)

Figure 4. Frequency responses of the optocoupler output stage impedance: (a) magnitude plots; (b) phase response plots. 


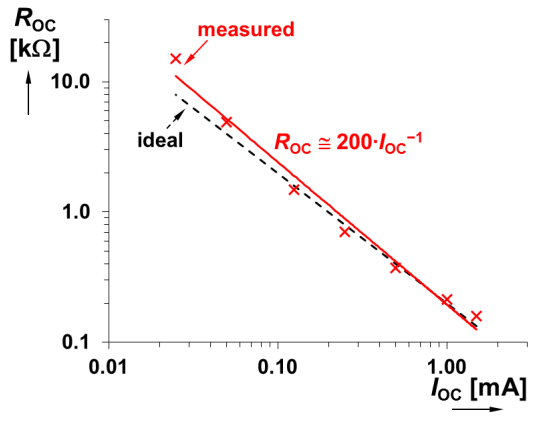

(a)

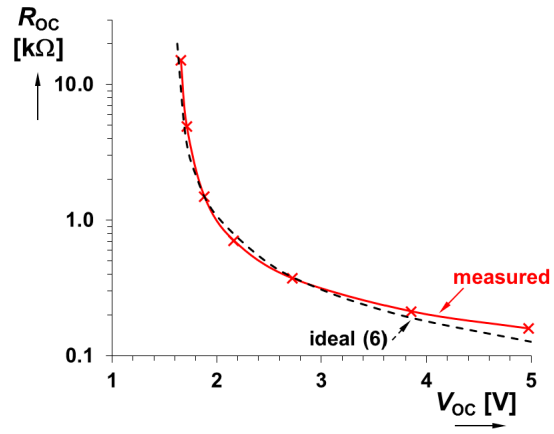

(b)

Figure 5. Dependence of $R_{O C}$ on: (a) driving current $I_{O C} ;(\mathbf{b})$ driving voltage $V_{O C}$.

Neglecting the discussed inequality of $I_{O C 1} \neq I_{O C 2}$, the ideal equation for the $\mathrm{FO}\left(f_{0 i}\right)$ controlled by the optocoupler can be written as:

$$
f_{0 i} \cong \frac{V_{O C}-V_{\text {th }}}{2 \pi \cdot 0.2 \cdot\left(0.5 R_{\text {pot }}+R_{m 1,2}\right) \sqrt{C_{1} C_{2}}} \cong \frac{V_{O C}-1.6}{2 \pi \cdot 432 \cdot \sqrt{C_{1} C_{2}}} .
$$

Note that this equation supposes the identical behavior of both optocouplers. A more accurate relation (especially for operations with very low values of $C_{1,2}$; above $1 \mathrm{MHz}$ ) for the $\mathrm{FO}\left(f_{0 e}\right)$ can be obtained for real values of parasitic features included in Equation (5c). We expect identical values $R_{\mathrm{X} 1}=R_{\mathrm{X} 2}=R_{\mathrm{X}}=95 \Omega$ (and $C_{p 1}=3 \mathrm{pF}, C_{p 2}=10 \mathrm{pF}$ ) in the following expression:

$$
f_{0 e} \cong \frac{1}{2 \pi \cdot\left[0.2 \cdot\left(\frac{0.5 R_{p o t}+R_{m 1,2}}{V_{O C}-V_{t h}}\right)+R_{X}\right] \cdot \sqrt{\left(C_{1}+C_{p 1}\right)\left(C_{2}+C_{p 2}\right)}} .
$$

The experimental results of the FO of the oscillator in Figure 3, including the AGC from Figure 2, are summarized in Table 3. The implemented optocouplers offer a range of $R_{O C}$ adjustability, from approximately $130 \Omega$ to $2.7 \mathrm{k} \Omega\left(I_{O C}\right.$ varied from $75 \mu \mathrm{A}$ to $\left.1500 \mu \mathrm{A}\right)$ in the ideal case and from $150 \Omega$ to $2.8 \mathrm{k} \Omega$ in the measured case, see Table 3 for the detailed results. The expected trace includes the abovementioned parasitic elements. These results are represented graphically in Figure 6a, and the FO dependences for the driving of the oscillator by $V_{O C}$ voltage are shown in Figure $6 \mathrm{~b}$. The traces in Figure $6 \mathrm{~b}$ represent the ideal (Equation (7)), expected (Equation (8), including the nodal parasitics of the circuit), and the additional nodal capacitances $(10 \mathrm{pF})$ expected in the case of the real printed circuit board. Finally, the measured results are very close to the case in which PCB parasitics are considered. The CO for the influenced circuit (as derived in Equation (5b)) is fulfilled theoretically for $B \geq 1.12$.

There are several reasons for the differences between the ideal, expected, and experimental behaviors (results of frequency dependences on $V_{O C}$ in Table 3 and Figure 6b): (a) parasitic elements (capacities) of the active element due to the close values of the working capacitors to the stray capacitances; (b) transit features of active devices (their phase responses are especially important for oscillators-these issues occur at frequencies lower than $-3 \mathrm{~dB}$ cut-off or transit frequency); (c) Miller effect of the increasing input capacity of active devices (amplifiers) when the gain is varied-the "parasitic capacity" increases with increasing gain of blocks of the circuit; this behavior is not easily predictable and implementable to the design equations; (d) high uncertainties in bands above $1 \mathrm{MHz}$ given by real parasitic features of the PCB (parasitic conductivity, inductance, and capacity) that can be only approximately estimated in the case of capacity - the accuracy and high-frequency (RF) behavior of circuits operating above $1 \mathrm{MHz}$ highly depends on the design and quality of the PCB; and (e) inequality of the driving current of optocouplers $\left(I_{O C 1} \neq I_{O C 2}\right)$. 
Table 3. Comparison of ideal, expected, and measured (experimental) FO dependences on driving parameters.

\begin{tabular}{|c|c|c|c|c|c|c|c|c|c|}
\hline$V_{O C}(\mathrm{~V})$ & $\begin{array}{l}I_{O C} \\
(\mu \mathrm{A})\end{array}$ & $\begin{array}{c}R_{O C i} \\
(\Omega)\end{array}$ & $\begin{array}{c}R_{\text {OCmeas }} \\
(\Omega)\end{array}$ & $\begin{array}{c}R_{O C i}+ \\
R_{X 1,2}(\Omega)\end{array}$ & $\begin{array}{c}R_{\text {OCmeas }}+ \\
R_{X 1,2}(\Omega)\end{array}$ & $\begin{array}{c}f_{0 i} \\
\text { (MHz) }\end{array}$ & $\begin{array}{c}f_{0 e} \\
\text { (MHz) }\end{array}$ & $\begin{array}{c}f_{0 e+10 \mathrm{pF}} \\
(\mathrm{MHz})\end{array}$ & $\begin{array}{l}f_{0 m e a s} \\
\text { (MHz) }\end{array}$ \\
\hline 4.95 & 1500 & 133 & 152 & 228 & 247 & 25.27 & 13.32 & 11.21 & 10.30 \\
\hline 3.74 & 884 & 226 & 227 & 321 & 322 & 16.78 & 10.05 & 8.46 & 8.01 \\
\hline 2.82 & 500 & 400 & 366 & 495 & 461 & 9.57 & 6.64 & 5.59 & 6.02 \\
\hline 2.23 & 280 & 714 & 629 & 809 & 724 & 5.18 & 3.98 & 3.35 & 4.00 \\
\hline 2.04 & 193 & 1039 & 936 & 1134 & 1030 & 3.45 & 2.77 & 2.33 & 3.01 \\
\hline 1.86 & 123 & 1633 & 1524 & 1727 & 1620 & 2.04 & 1.70 & 1.43 & 2.01 \\
\hline 1.73 & 75 & 2667 & 2780 & 2762 & 2880 & 1.04 & 0.89 & 0.75 & 1.05 \\
\hline
\end{tabular}

Notes: symbols of subscripts: $i$-ideal value (7), $e$ - expected value (8), $e+10 \mathrm{pF}$-expected value (8) including the effect of PCB in each high-impedance node of working $C_{1,2}$.

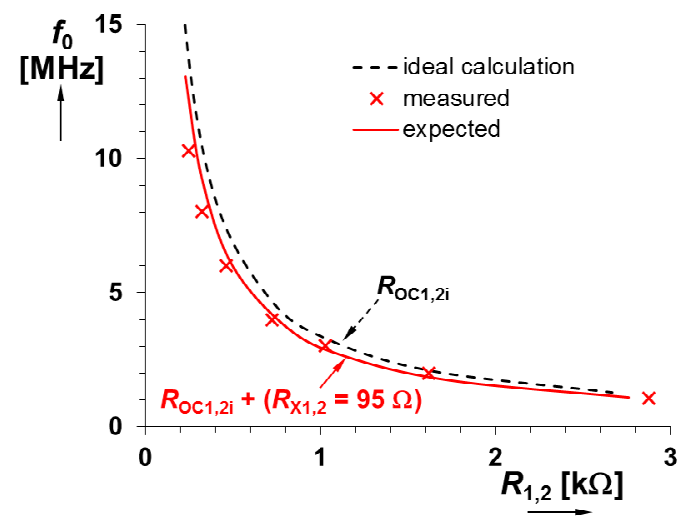

(a)

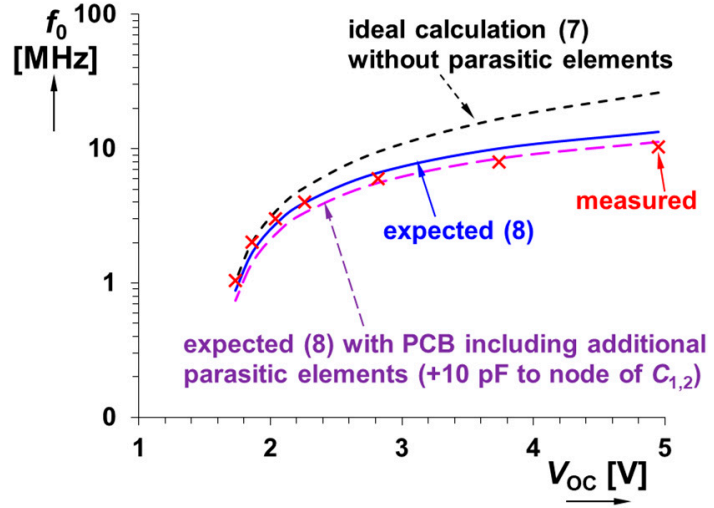

(b)

Figure 6. Dependences of FO on: (a) $R_{1,2}$ (formed by $R_{O C 1,2}$ only or $R_{O C 1,2}$ influenced by $R_{X 1,2}=95 \Omega$ ); (b) $V_{O C}$ (traces obtained from ideal, expected, and measured results).

The ideal calculation (ideal values of $C_{1,2}$ and $R_{O C 1,2}$ ) supposes a range of the FO tunability of $1.04 \mathrm{MHz} \rightarrow 25.27 \mathrm{MHz}$. Calculations including all important parasitic effects estimate a range of $0.89 \mathrm{MHz} \rightarrow 13.32 \mathrm{MHz}\left(R_{1,2}\right.$ varied from 247 to $2.88 \mathrm{k} \Omega$ ). Consideration of the additional PCB effect $(+10 \mathrm{pF})$ leads to a range of $0.75 \rightarrow 11.21 \mathrm{MHz}$. The experimental values follow our expectations because the measured $\mathrm{FO}$ yields a range of $1.05 \rightarrow 10.30 \mathrm{MHz}$.

Output amplitudes $\left(V_{C 1}\right.$ and $\left.V_{C 2}\right)$ reach levels of about $200 \mathrm{mV}_{p-p}$ and $300 \mathrm{mV}_{p-p}$ (based on the setting of the AGC) and they remain almost constant during the tuning process (Figure 7a). Their ratio confirms the validity of Equation (4). The phase shift of both signals is around 45 degrees (Figure $7 \mathrm{~b}$ ). This value was obtained from the oscilloscope in the time-domain measurement by the automatic function evaluating the distance at which signals at both channels cross 0 . An example of transient responses for $V_{O C}=4.95 \mathrm{~V}\left(f_{\text {omeas }}=10.30 \mathrm{MHz}\right)$ is shown in Figure 8. Their spectral analysis provided the results shown in Figure 9. The THD varies between approximately 0.7 and 3.3\%. Quite high values are given by the low suppression of higher harmonic components of the active device itself (especially by the high-speed device OPA615 [28], only about $35 \mathrm{dBc}$ in $\mathrm{MHz}$ bands). Similarly, the implementation of many nonlinear high-speed devices results in a certain presence of somewhat influential intermodulation products (visible in transient responses as superposed fluctuations at peaks of amplitudes as well as some combination products observed in the spectral analysis around the fundamental tone). The overall power consumption of the testbed (including buffers and opamps in AGC) reaches $570 \mathrm{~mW}$ (five IC devices, approximately $60 \mathrm{~mA}$ of power current per supply branch, $\pm 5 \mathrm{~V}$ ). 


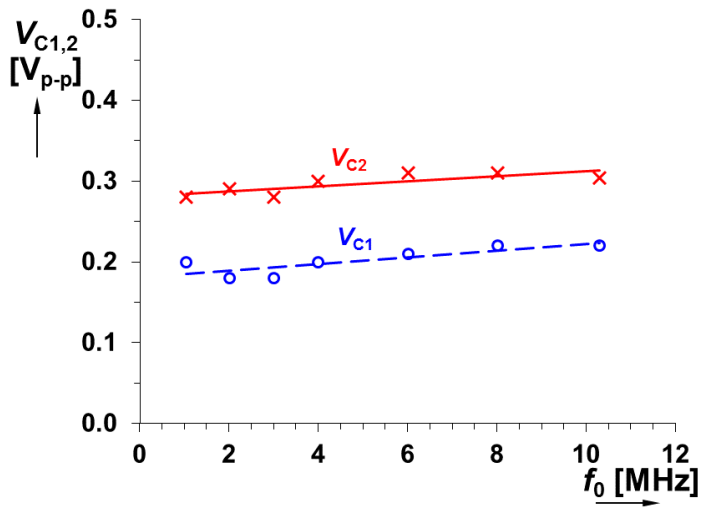

(a)

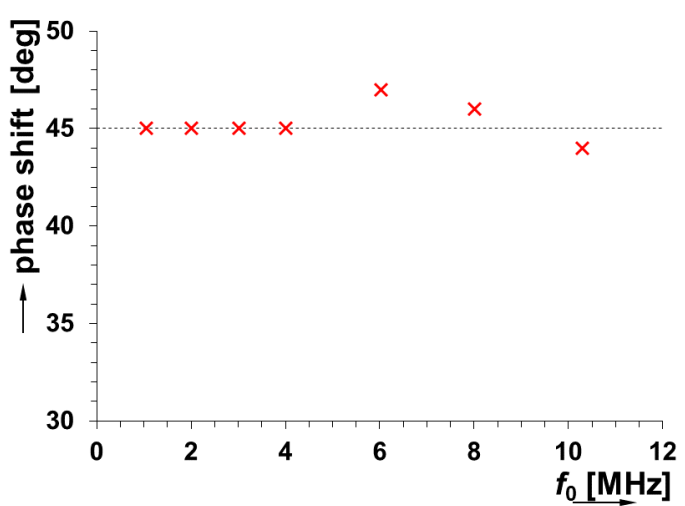

(b)

Figure 7. Effects of the FO tuning on the generated signals: (a) dependence of output levels on the FO, (b) dependence of phase shift on the FO.

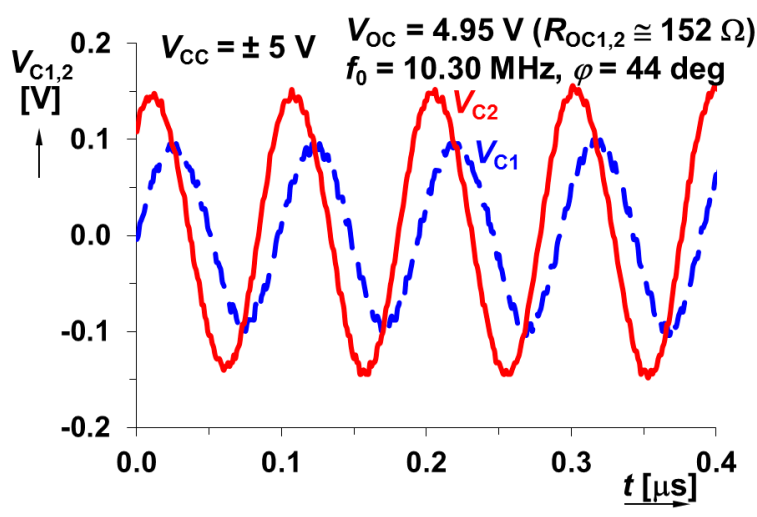

Figure 8. Example of the produced output waveforms in time domain at the end of designed range of the FO adjustment.

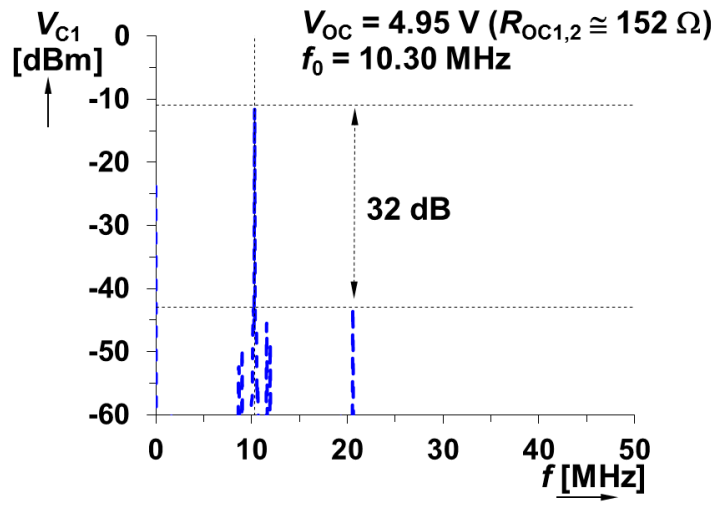

(a)

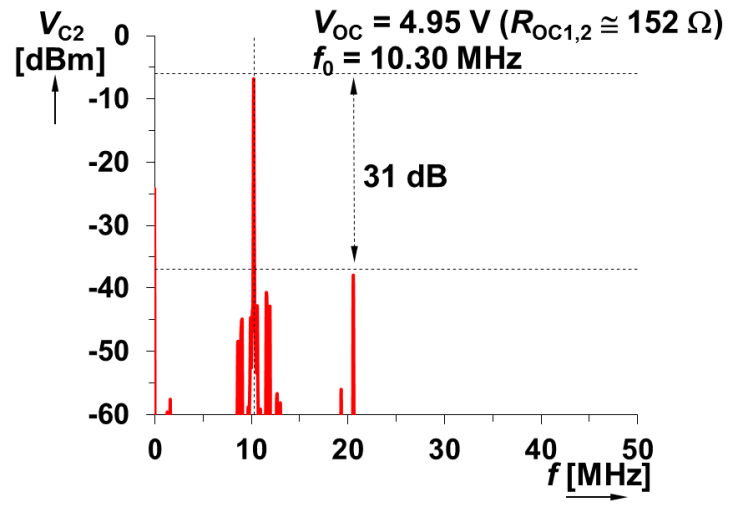

(b)

Figure 9. Spectrum of generated waveforms at the end of designed range of the FO adjustment: (a) $V_{C 1}$;

(b) $V_{C 2}$.

We replaced values of capacitors in the oscillator in order to demonstrate the maximal available FO in the experimentally tested prototype for a still practically feasible value $\left(C_{1,2}=4.7 \mathrm{pF}\right.$ was selected). Then, the value $f_{0}=25 \mathrm{MHz}$ was set experimentally by $V_{O C}=4.55 \mathrm{~V}$. The results of the spectral analysis 
are shown in Figure 10 for both output waveforms. Images of the measured prototype are given in Figure 11.

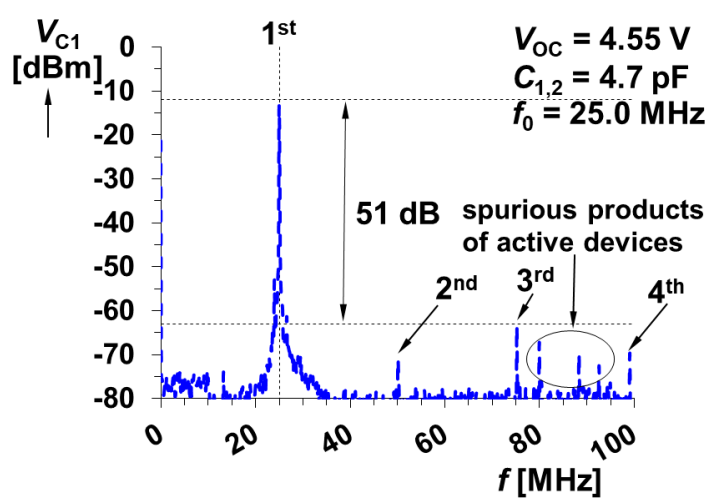

(a)

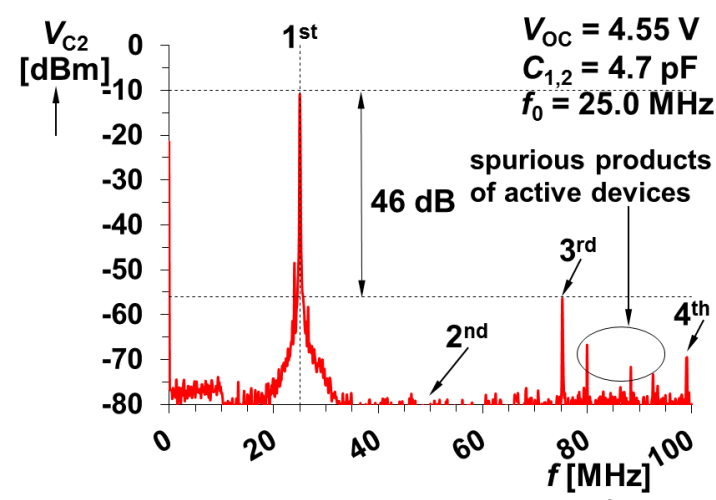

(b)

Figure 10. Spectrum of generated waveforms for $C_{1,2}=4.7 \mathrm{pF}$ and $V_{O C}=4.55 \mathrm{~V}$ : (a) $V_{C 1} ;$ (b) $V_{C 2}$.

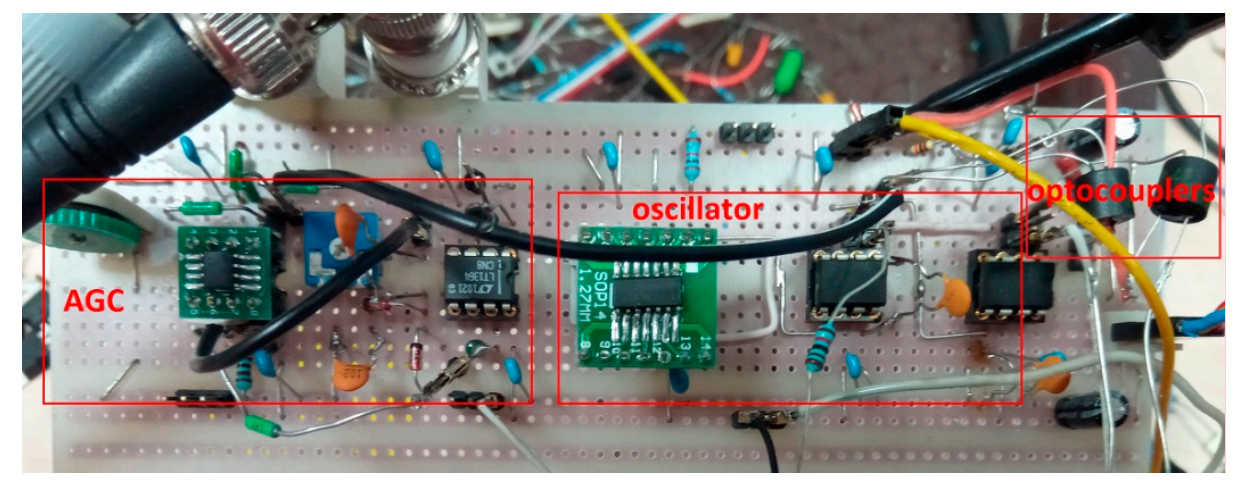

Figure 11. Measured prototype developed for experimental purposes.

The phase noise evaluation is shown in Figure 12 for $V_{C 2}$ output (these values are actually almost identical for both outputs). The phase noise value was obtained for offset frequency $\Delta f_{\text {offset }}=10 \mathrm{kHz}$ and $100 \mathrm{kHz}\left(1 / 1000\right.$ and $1 / 100$ of fundamental tone; the oscillator frequency was set to $f_{0} \cong 10 \mathrm{MHz}$ by $V_{O C}=4.92 \mathrm{~V}$ for this test). The phase noise values of 45 and $47 \mathrm{dBc} / \mathrm{Hz}$ were obtained for these values of offset frequencies. Note that these are only approximate values due to the limited accuracy of measurement (the noise background is influenced by the resolution-bandwidth (RBW) of the spectrum analyzer that was set to $10 \mathrm{~Hz}$ in all cases). The value in the range of $40 \rightarrow 70 \mathrm{dBc} / \mathrm{Hz}$ is typical for these types of circuits due to the usage of inertial AGC (it solves limitation, shape distortion, THD, and the variation of output levels when $f_{0}$ is tuned, but its drawback is the higher fluctuation/jitter of output amplitudes). Radio-frequency (GHz)-targeted solutions reach values in the high tens of $\mathrm{dBc} / \mathrm{Hz}$ (for example $>100 \mathrm{dBc} / \mathrm{Hz}$ ) in dependence on $\Delta f_{\text {offset }}$ because there is no AGC system in narrow-band tunable oscillators and higher spurious spectral products are filtered. However, this approach cannot be used in base-band or inter-frequency-band oscillators tunable in the $f_{0}$ range of 10:1 or more. Note that the phase noise and $f_{0}$ stability (except AGC) also depend on the precision of the construction of the circuit (quality of the PCB, etc.). It may significantly influence overall performances, especially at high frequencies above $1 \mathrm{MHz}$. The fundamental tone slightly fluctuates in the results shown in Figure 12. The frequency change achieves $\pm 33 \mathrm{kHz}\left( \pm 0.33 \%\right.$ at $\left.f_{0} \cong 10 \mathrm{MHz}\right)$, which results in a frequency stability of $S\left(f_{0}\right)=\left|\Delta f_{0} / f_{0}\right|=6.6 \times 10^{-3}$ (being within the typical range for active RC oscillators). 


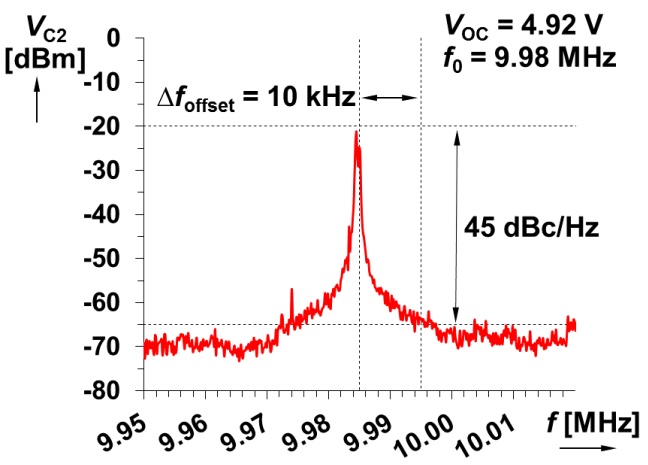

(a)

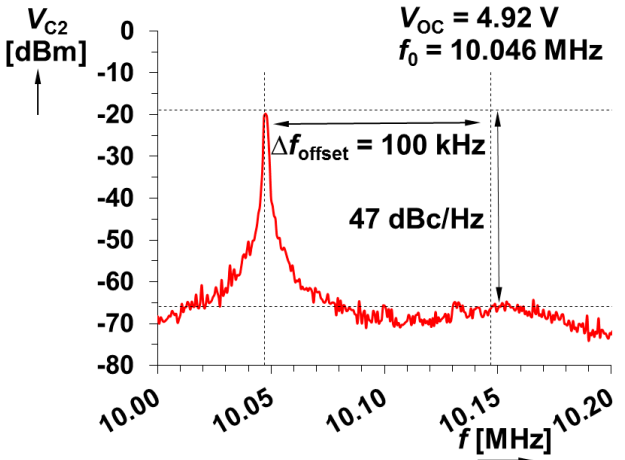

(b)

Figure 12. Spectral analysis for phase noise measurement at $V_{C 2}$ : (a) offset frequency $10 \mathrm{kHz} ;(\mathbf{b})$ offset frequency $100 \mathrm{kHz}$.

\section{Discussion of Other Methods of Indirect Electronic Control of FO}

The position of the resistor $R_{1}$ is not very beneficial due to the floating (between two nodes) connection to the circuit. The method discussed in the previous paragraphs implemented optocouplers; however, there are also other possibilities that should be briefly discussed (their main advantages and disadvantages). Table 4 reveals their general comparison.

The replacement of $R_{1,2}$ by junction field effect transistors (J-FET) in a triode/ohmic/linear regime $[11,12,33-35]$ can be easily applied. However, there are some restrictions. It is not easy to maintain a transistor in a linear regime $\left(V_{\mathrm{DS}}<V_{\mathrm{GS}}-V_{t h}\right)$ even for increasing processed signal levels in nodes where transistors are connected. Transistors behave highly nonlinearly for voltage levels higher than several tens of $\mathrm{mV}$, and nonlinearity increases for increased resistance $\left(r_{\mathrm{DS} o n}\right)$ driven by $V_{\mathrm{GS}}$ voltage. The range of the $r_{\mathrm{DS} o n}$ resistance adjustability can be large (N type J-FET BF245A [36]: $200 \Omega \rightarrow 2 \mathrm{k} \Omega$ for $0 \rightarrow-2 \mathrm{~V}$ ); however, the nonlinearity of $V_{\mathrm{DS}}$ vs. $I_{\mathrm{D}}$ plots plays a significant role, especially for high values of resistances (high $V_{\mathrm{GS}}$ ). Unfortunately, there is no other way in the IC design practice. One example of J-FET implementation was experimentally tested in our oscillator (Figure 1). Figure 13 illustrates the output level for the $V_{C 1}$ wave that is significantly distorted (THD $>13 \%$ ) by nonlinearity with increased values of $r_{\mathrm{DS}}$. The amplitude is not limited but the shape and symmetry of the positive half-wave vs. negative half-wave is significantly damaged. The linearization of the transistor can be provided by two additional resistors [33]; however, the linearization of the floating form of an electronically controllable equivalent is not an easy task (many additional active and passive devices are required) [34,35].

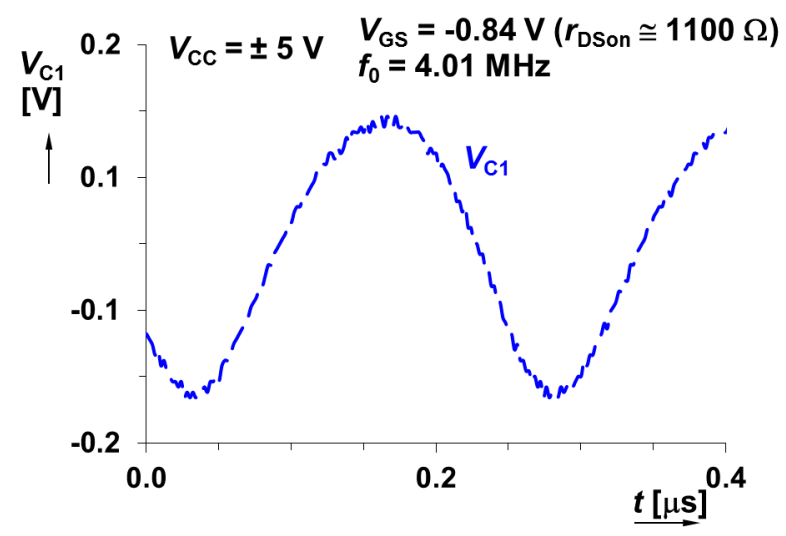

Figure 13. The example of distorted waveform by nonlinear effects of junction field effect transistors (J-FET) replacing resistors. 
Table 4. Comparison of the methods for indirect FO tunability (standard potentiometer shown for reference purposes).

\begin{tabular}{|c|c|c|c|c|c|c|c|}
\hline Method & $\begin{array}{l}\text { Frequency } \\
\text { Features }\end{array}$ & $\begin{array}{l}\text { Dynamical } \\
\text { Features }\end{array}$ & Linearity & $\begin{array}{l}\text { Response } \\
\text { on Control }\end{array}$ & Value Range & $\begin{array}{c}\text { Significant } \\
\text { Additional } \\
\text { Power } \\
\text { Consumption }\end{array}$ & Notes \\
\hline $\begin{array}{c}\text { Resistor } \\
\text { (potentiometer) }\end{array}$ & $\operatorname{good} *$ & good & good & fast & $\begin{array}{l}\text { large (several } \\
\text { decades) }\end{array}$ & No & $\begin{array}{l}\text { mechanical } \\
\text { features }\end{array}$ \\
\hline $\begin{array}{l}\text { Optocoupler with } \\
\text { resistive output }\end{array}$ & good* & $\begin{array}{c}\text { good } \\
\text { (hundreds } \\
\text { of } \mathrm{mV} \text { ) }\end{array}$ & $\begin{array}{l}\text { good (nonlinear } \\
\text { deviation up to } \\
\text { units of \%) }\end{array}$ & $\begin{array}{c}\text { average } \\
\text { (units of } \mathrm{ms} \text { ) }\end{array}$ & large & No & - \\
\hline $\begin{array}{l}\text { J-FET (or unipolar } \\
\text { transistor) }\end{array}$ & good & $\begin{array}{l}\text { bad (tens } \\
\text { of } \mathrm{mV} \text { ) }\end{array}$ & $\begin{array}{c}\text { bad (nonlinear } \\
\text { deviation tens of \%) }\end{array}$ & fast & large & No & $\begin{array}{c}\text { maintain in } \\
\text { linear regime }\end{array}$ \\
\hline $\begin{array}{c}\text { Digital } \\
\text { potentiometer }\end{array}$ & $* *$ & good & good & $* *$ & $\begin{array}{l}\text { limited (number } \\
\text { of switched } \\
\text { segments/bits) }\end{array}$ & Yes & $\begin{array}{l}\text { discontinuous } \\
\text { adjusting }\end{array}$ \\
\hline $\mathrm{D} / \mathrm{A}$ converter & $* * *$ & good & good & $* * *$ & $\begin{array}{l}\text { limited (number } \\
\text { of bits) }\end{array}$ & Yes & $\begin{array}{l}\text { discontinuous } \\
\text { adjusting }\end{array}$ \\
\hline $\begin{array}{c}\text { Active analog } \\
\text { solution (OTA for } \\
\text { example) }\end{array}$ & good & average/bad & average/bad & fast & $\begin{array}{l}\text { limited (can be } \\
\text { even less than a } \\
\text { decade for MOS } \\
\text { solution) }\end{array}$ & Yes & - \\
\hline
\end{tabular}

Notes: * values in hundreds of $\Omega$ (parallel parasitic capacity insignificant); ${ }^{* *}$ there are types having a high number of steps (1024) but their frequency features and parasitic capacities are not beneficial (bandwidth about $100 \mathrm{kHz}$, tens of $\mathrm{pF})$. There are also types having a wider bandwidth $(>10 \mathrm{MHz})$ but with a very low number of steps $(<256)$ that may not be sufficient for the fine control of the condition of oscillation or frequency tuning in oscillators in these bands; the responses depend on the type of bus (serial/parallel) and speed of control logic (tens of $\mu$ s but also tens of ms for specific type); ${ }^{* * *}$ allows wideband (tens of MHz and more) features, fast for specified bandwidths but very expensive and requires high power consumption.

Digital potentiometers [37-40] are widespread parts serving in control and adjustable systems, especially for low-frequency circuits. They have the advantage of simple digital controllability of value; however, many drawbacks limit their practical usability in medium- and high-frequency systems. These issues consist in real parasitic resistance of the middle terminal (wiper), large parasitic capacitances (tens of $\mathrm{pF}$ ), and therefore very bad frequency features (only tens-hundreds of $\mathrm{kHz}$ in many cases). Discontinuous adjustment of the value (based on the number of bits) can be also considered as a drawback for specific applications (the control of amplitude stabilization, for example). Also, the reaction on changes (depending on the construction of specific types and their internal control logic) can be very slow. Therefore, the majority of these devices are unsuitable for the FO tuning in the range presented in this paper.

Similar features are offered by D/A converters (they can establish controllable resistors [41]). However, modern and very fast (Gsps) solutions can be prepared for high-frequency operation. Unfortunately, the power consumption is enormous (power supply currents in hundreds of $\mathrm{mA}$ ) and the price reaches tens of dollars. This renders this method unsuitable for compact designs and solutions.

Active solutions (a floating resistor can be implemented by two OTAs [30,31]) may have a very good frequency response and fast reaction on changes (adjusting of the driving voltage). However, active solutions (especially OTA-based solutions without linearization [30]) have substantial problems with linearity and dynamical restrictions. The range of the equivalent resistance value can also be very limited (especially in MOS solutions where square laws [42,43] for currents are valid).

The following discussion evaluates the features of the proposed analog solution and direct digital synthesis (DDS). Advantages of DDS are clear: wide bandwidth (hundreds of MHz), simple configurability, stable operation, excellent phase noise (but this parameter is significant for bands starting at hundreds of $\mathrm{MHz}$, not for the bands observed in this paper), immunity to aging of parameters, minimized temperature effects, high accuracy, etc. On the other hand, many DDS chips generate only single-phase waveforms ( $70-80 \%$ of production). The generation of more than one waveform requires the interconnection of several chips or multichannel DDS (conferring a significantly higher power consumption and cost). DDS chips require an external clock generator (additional 
complication and power consumption) in some cases. The frequency is not continuously tunable. The power current reaches hundreds of $\mathrm{mA}$. A DDS must be equipped with some microcontroller and / or supporting peripheral devices (USB connection, interface, clock generator $=$ additional power consumption), or DDS development boards are used in many designs (several times higher cost). The cost of the complete designed analog oscillator in this paper (elements used in implementation) reaches approximately 30 Euros, the cost of the multichannel DDS (AD9959 for example) chip (with only the chip ready for implementation) reaches 40 Euros, and the cost of the complete operating development board with DDS is several times higher (approximately 350 Euros). Therefore, advantages coming from the utilization of DDS can be overcome by a low-cost solution with acceptable features for the intended application.

The main advantages of the proposed analog solution in comparison to DDS are: (a) simplicity of the resulting circuit and tunability method (an integrated DDS has a much more complex block topology and a higher complexity of internal blocks-it cannot be implemented in discrete form in practice); (b) low cost (for the intended bandwidth—up to low tens of $\mathrm{MHz}$ ); (c) immediate response of frequency on changes (no delay); (d) no requirement for additional peripheral devices (clock generator, interfaces, etc.); (e) no requirement of programming (the approximate final costs noted above do not take the controlling software for multiphase generation and the tuning of the DDS into account). Of course, there are also disadvantages: (a) influence of temperature and aging effects on frequency stability; (b) low value of phase noise and worse stability (however, this issue is usually not evaluated/solved in the case of similar solutions in studied bands of units-low tens of $\mathrm{MHz}$ ); (c) the accuracy of frequency setting is influenced by parasitic elements. The proposed device's power consumption is comparable to that of the DDS (due to low supply voltage of $1.8 \mathrm{~V}$ of AD9959, for example), but the supply current is several times lower in comparison to DDS.

Therefore, similar analog solutions are worth investigation at bands where high-speed opamps and other active elements are still competitive (up to several tens of $\mathrm{MHz}$ ). It really depends on the application and quality of the application to determine whether a digital or analog solution should be selected and, of course, it depends on the budget available for construction.

\section{Conclusions}

We designed and tested the topology of a sine wave two-phase oscillator with output waveforms having a $\pi / 4$ phase shift. The phase shift of 45 degrees is suitable as a local source for multiphase generation [1]. It can be further implemented in the modulation process (PSK—phase shift keying) or multistate modulation techniques requiring wideband tunability [44]. The designed circuit brings several benefits: (a) the low number of components (two grounded $C, 2 R$ ); (b) simple topology using only two three-port active elements; (c) wide tunability (indirectly proportional to the resistance value) of the frequency of oscillations; (d) constant amplitudes when the FO is tuned; (e) simple implementation of the independently controllable (voltage-controlled) condition for oscillation; (f) minimal additional power consumption in comparison with the implementation of full active devices, digital potentiometers, digital-to-analog converters (DACs), etc. for purposes of FO tunability. The experimental tests employing optocouplers at positions of both resistors (floating and grounded) confirmed the intentions and operation of the design in the range from approximately $1 \mathrm{MHz}$ to $10 \mathrm{MHz}$ (ratio 10:1) by driving the control voltage between 1.7 and $5 \mathrm{~V}$ (ratio 3:1). So, a large readjustment is not allowed when only a single resistor value is intended to be used for frequency tuning, similar to the method of so-called single-resistance-controlled oscillators [2-13]. The output amplitudes sustained 100 and $150 \mathrm{mV}$ (THD between 0.7 and 3.3\%) when the frequency of the oscillator was tuned. Sensitivities of proposed solution achieved the standard and low value of -0.5 . A possibility of the implementation of the both resistors for tuning purposes and their replacement by suitable electronically controllable equivalents (optocouplers with resistive outputs stage) can be seen as inspiration for many interesting topologies of oscillators (a great overview is available in References [45,46]), where the presented method of tuning can be beneficially implemented. 
Author Contributions: Conceptualization, R.S. and J.J.; Methodology, R.S.; Validation, R.S., J.J., and L.L.; Formal Analysis, J.D.; Investigation, R.S. and J.J.; Data Curation, L.L. and J.D.; Writing-Original Draft Preparation, R.S., J.J., L.L., and J.D.; Writing—Review and Editing, R.S., J.J., L.L., and J.D.

Funding: This research was funded by the Czech Ministry of Education through the National Sustainability Program under grant LO1401.

Acknowledgments: Research described in this paper was financed by Czech Ministry of Education in frame of National Sustainability Program under grant LO1401. For research, infrastructure of the SIX Center was used.

Conflicts of Interest: The authors declare no conflict of interest. The funders had no role in the design of the study; in the collection, analyses, or interpretation of data; in the writing of the manuscript, and in the decision to publish the results.

\section{References}

1. Senani, R.; Bhaskar, D.R.; Singh, V.K.; Sharma, R.K. Sinusoidal Oscillators and Waveform Generators Using Modern Electronic Circuit Building Blocks; Springer International Publishing AG: Cham, Switzerland, 2016; pp. 1-622, ISBN 978-3-319-23712-1. [CrossRef]

2. Senani, R.; Bhaskar, D.R.; Singh, A.K. Current Conveyors: Variants, Applications and Hardware Implementations, 1st ed.; Springer: Berlin/Heidelberg, Germany, 2015; ISBN 978-3-319-08684-2. [CrossRef]

3. Liu, S.-I. Single-resistance-controlled/voltage-controlled oscillator using current conveyors and grounded capacitors. Electron. Lett. 1995, 31, 337-338. [CrossRef]

4. Abuelmaatti, M.T.; Ghumaiz, A.-A. Novel CCI-based Single-Element-Controlled Oscillators Employing Grounded Resistors and Capacitors. IEEE Trans. Circuits Syst. I Fundam. Theory Appl. 1996, 43, 153-155. [CrossRef]

5. Senani, R.; Singh, V.K. Novel single-resistance-controlled-oscillator configuration using current-feedbackamplifiers. IEEE Trans. Circuits Syst. I Fundam. Theory Appl. 1996, 43, 698-700. [CrossRef]

6. Martinez, P.A.; Sabadell, J.; Aldea, C. Grounded resistor controlled sinusoidal oscillator using CFOAs. Electron. Lett. 1997, 33, 346-348. [CrossRef]

7. Gupta, S.S.; Senani, R. State variable synthesis of single resistance controlled grounded capacitor oscillators using only two CFOAs. IEE Proc. Circuits Devices Syst. 1998, 145, 135-138. [CrossRef]

8. Gupta, S.S.; Senani, R. State variable synthesis of single resistance controlled grounded capacitor oscillators using only two CFOAs: Additional new realisations. IEE Proc. Circuits Devices Syst. 1998, 145, 415-418. [CrossRef]

9. Soliman, A.M. Synthesis of grounded capacitor and grounded resistor oscillators. J. Frankl. Inst. 1999, 336, 735-746. [CrossRef]

10. Khan, A.A.; Bimal, S.; Dey, K.K.; Roy, S.S. Novel RC Sinusoidal Oscillator Using Second-Generation Current Conveyor. IEEE Trans. Inst. Meas. 2005, 54, 2402-2406. [CrossRef]

11. Bhaskar, D.R.; Senani, R. New CFOA-Based Single-Element-Controlled Sinusoidal Oscillators. IEEE Trans. Inst. Meas. 2006, 55, 2014-2021. [CrossRef]

12. Gupta, S.S.; Bhaskar, D.R.; Senani, R. New voltage controlled oscillators using CFOAs. AEU-Int. J. Electron. Commun. 2009, 63, 209-217. [CrossRef]

13. Abuelmaatti, M.T. Identification of a class of two CFOA-based sinusoidal RC oscillators. Analog Integr. Circuits Signal Proc. 2010, 65, 419-428. [CrossRef]

14. Kumngern, M.; Junnapiya, S. A sinusoidal oscillator using translinear current conveyors. In Proceedings of the IEEE International Asia Pacific Conference on Circuits and Systems (APCCAS), Kuala Lumpur, Malaysia, 6-9 December 2010; pp. 740-743. [CrossRef]

15. Lahiri, A.; Jaikla, W.; Siripruchyanun, M. Explicit-current-output second-order sinusoidal oscillator using two CFOAs and grounded capacitors. AEU-Int. J. Electron. Commun. 2011, 65, 669-672. [CrossRef]

16. Lahiri, A.; Gupta, M. Realizations of Grounded Negative Capacitance Using CFOAs. Circuits Syst. Signal Proc. 2011, 30, 143-155. [CrossRef]

17. Lahiri, A. Current-mode variable frequency quadrature sinusoidal oscillators using two CCs and four passive components including grounded capacitors. Analog Integr. Circuits Signal Proc. 2012, 71, 303-311. [CrossRef]

18. Chen, H.-P.; Hsien, M.-Y.; Lin, C.-C.; Huang, W.-Y. CFOA-based quadrature oscillator employing grounded capacitors. In Proceedings of the IEEE International Conference on Information Science, Electronics, and Electrical Engineering (ISEEE), Sapporo, Japan, 26-28 April 2014; pp. 470-473. [CrossRef] 
19. Bajer, J.; Lahiri, A.; Biolek, D. Current-mode CCII+ Based Oscillator Circuits using a Conventional and a Modified Wien-Bridge with All Capacitors Grounded. Radioengineering 2011, 20, 245-250.

20. Sotner, R.; Jerabek, J.; Prokop, R.; Kledrowetz, V.; Polak, J.; Fujcik, L.; Dostal, T. Practically Implemented Electronically Controlled CMOS Voltage Differencing Current Conveyor. In Proceedings of the IEEE 59th International Midwest Symposium on Circuits and Systems (MWSCAS), Abu Dhabi, UAE, 16-19 October 2016; pp. 667-670. [CrossRef]

21. Biolkova, V.; Bajer, J.; Biolek, D. Four-Phase Oscillators Employing Two Active Elements. Radioengineering 2011, 20, 334-339.

22. Biolek, D.; Senani, R.; Biolkova, V.; Kolka, Z. Active elements for analog signal processing: Classification, Review and New Proposals. Radioengineering 2008, 17, 15-32.

23. Surakampontorn, W.; Thitimajshima, W. Integrable electronically tunable current conveyors. IEE Proc. G 1988, 135, 71-77. [CrossRef]

24. Fabre, A.; Mimeche, N. Class A/AB second-generation current conveyor with controlled current gain. Electron. Lett. 1994, 30, 1267-1268. [CrossRef]

25. Minaei, S.; Sayin, O.K.; Kuntman, H. A new CMOS electronically tunable current conveyor and its application to current-mode filters. IEEE Trans. Circuits Syst. I 2006, 53, 1448-1457. [CrossRef]

26. Sotner, R.; Jerabek, J.; Herencsar, N.; Hrubos, Z.; Dostal, T.; Vrba, K. Study of Adjustable Gains for Control of Oscillation Frequency and Oscillation Condition in 3R-2C Oscillator. Radioengineering 2012, 21, $392-402$.

27. Intersil (Elantec). EL2082 CN Current-Mode Multiplier (Datasheet); 1996; 14p. Available online: http: / / www.intersil.com/data/fn/fn7152.pdf (accessed on 18 August 2018).

28. Texas Instruments. OPA615 Wide Bandwidth, DC Restoration Circuit (Datasheet); 2009; 33p. Available online: http:/ / www.ti.com/lit/ds/symlink/opa615.pdf (accessed on 18 August 2018).

29. Texas Instruments. OPA2652 SpeedPlus Dual, $700 \mathrm{MHz}$, Voltage-Feedback Operational Amplifier (Datasheet); 2006; 23p. Available online: https://www.ti.com/lit/ds/symlink/opa2652.pdf (accessed on 18 August 2018).

30. Sanchez-Sinencio, E.; Silva-Martinez, J. CMOS transconductance amplifiers, architectures and active filters: A tutorial. IEE Proc. Circuits Devices Syst. 2000, 147, 3-12. [CrossRef]

31. Geiger, R.L.; Sanchez-Sinencio, E. Active filter design using operational transconductance amplifiers: A tutorial. IEEE Circuits Devices Mag. 1985, 1, 20-32. [CrossRef]

32. Luna Optoelectronics. NSL-32SR3 Optocoupler (Datasheet); 2016; 2p. Available online: http://lunainc.com/ wp-content/uploads/2016/06/NSL-32SR3.pdf (accessed on 18 August 2018).

33. Nay, K.; Budak, A. A Voltage-Controlled Resistance with Wide Dynamic Range and Low Distortion. IEEE Trans. Circuits Syst. 1983, CAS-30, 770-772. [CrossRef]

34. Senani, R. Realisation of linear voltage-controlled resistance in floating form. Electron. Lett. 1994, 30, 1909-1910. [CrossRef]

35. Senani, R.; Bhaskar, D.R.; Gupta, S.S.; Singh, V.K. A configuration for realising floating, linear, voltage-controlled resistance, inductance and FDNC elements. Int. J. Circuit Theory Appl. 2009, 37, 709-719. [CrossRef]

36. ON Semiconductor. BF245A/B JFET VHF/UHF Amplifiers N-Channel-Depletion (Datasheet); 2001; 8p. Available online: https://www.onsemi.com/pub/Collateral/BF245A-D.PDF (accessed on 18 August 2018).

37. Analog Devices. Choosing the Correct digiPOT for Your Application (Application Note); $2014 ; 6 \mathrm{p}$. Available online: http:/ / www.analog.com/media/en/news-marketing-collateral/product-selection-guide/ Choosing_the_Correct_Digipot.pdf (accessed on 18 August 2018).

38. Sevcik, B. Modeling and Signal Integrity Testing of Digital Potentiometers. In Proceedings of the IEEE 17th International Conference Mixed Design of Integrated Circuits and Systems (MIXDES), Wroclaw, Poland, 24-26 June 2010; pp. 570-575.

39. Lunca, E.; Damian, C.; Petrisor, D.; Postolache, O. Programmable Active Filters Based on Digital Potentiometers. In Proceedings of the IEEE International Conference and Exposition on Electrical and Power Engineering (EPE), Iasi, Romania, 25-27 October 2012; pp. 787-791. [CrossRef]

40. Pandiev, I.M. Behavioral Modeling of CMOS Digital Potentiometers Using VHDL-AMS. In Proceedings of the IEEE International Power Electronics and Motion Control Conference (PEMC), Varna, Bulgaria, 25-28 September 2016; pp. 940-945. [CrossRef]

41. Maxim Integrated. DACs vs. Digital Potentiometers: Which Is Right for My Application? 2007; 1p. Available online: https:/ / www.maximintegrated.com/en/app-notes/index.mvp/id/4025 (accessed on 18 August 2018). 
42. Razavi, B. Design of Analog CMOS Integrated Circuits; McGraw-Hill: New York, NY, USA, 2001; ISBN 978-0072380323.

43. Gray, P.R.; Hurst, P.J.; Lewis, S.H.; Meyer, R.G. Analysis and Design of Analog Integrated Circuits, 5th ed.; Wiley: Hoboken, NJ, USA, 2009; ISBN 978-0470245996.

44. Rogers, J.W.M.; Plett, C.; Marsland, I. Radio Frequency System Architecture and Design; Artech House: London, UK, 2013; ISBN 978-1608075379.

45. Soliman, A.M. Two integrator loop quadrature oscillators: A review. J. Adv. Res. 2013, 4, 1-11. [CrossRef] [PubMed]

46. Abuelmaatti, M.T. Recent Developments in Current-Mode Sinusoidal Oscillators: Circuits and Active Elements. Arab. J. Sci. Eng. 2017, 42, 2583-2614. [CrossRef]

(c) 2018 by the authors. Licensee MDPI, Basel, Switzerland. This article is an open access article distributed under the terms and conditions of the Creative Commons Attribution (CC BY) license (http://creativecommons.org/licenses/by/4.0/). 